\title{
Corrosion Behavior of Coarse- and Fine-Grain Ni Coatings Incorporating NaH2PO4.H2O Inhibitor Treated Substrates
}

\author{
Anwar Ul-Hamid ${ }^{a *}$, Abdul Quddus ${ }^{a}$,Huseyin Saricimen ${ }^{a}$,Hatim Dafalla ${ }^{a}$ \\ ${ }^{a}$ Center for Engineering Research, Research Institute, King Fahd University of Petroleum \& Minerals, \\ P.O. Box 1524, Dhahran - 31261, Saudi Arabia
}

Received: November 19, 2013; Revised: January 7, 2015

\begin{abstract}
Plain carbon steel substrates were treated with NaH2PO4.H2O inhibitor for 24 hours and coated with Ni using dc and pulse electrodeposition in standard Watt's bath. The effect of dc and pulse electrodeposition, on the microstructure and corrosion properties of $\mathrm{Ni}$ coatings in $3.5 \mathrm{wt} \% \mathrm{NaCl}$ solution was studied. The effect of inhibitor on the deposition process and corrosion behavior was also examined. Materials characterization was performed using field emission scanning electron microscopy, cross-sectional scanning transmission electron microscopy, atomic force microscopy, $\mathrm{x}$-ray diffraction and nanoindentation. Experimental results indicated that pulse electrodeposition produced fine grained $\mathrm{Ni}$ coatings that showed lower corrosion rate compared to coarse grained dc electrodeposited Ni. Pretreatment of substrates with inhibitor did not adversely affect the deposition process and adherent $\mathrm{Ni}$ coatings were readily developed. The results showed that pulse electrodeposition could be used to produce hard corrosion resistant $\mathrm{Ni}$ coatings while the inhibitor treatment yielded enhanced corrosion protection by providing a protective buffer layer between the Ni coating and the substrate.
\end{abstract}

Keywords: corrosion, microstructure, Nickel (Ni), electrodeposition, inhibitor, NaH2PO4.H2O, sodium dihydrogen orthophosphate

\section{Introduction}

Nickel is commonly employed to enhance surface properties of various materials using electroless or electrolytic methods ${ }^{1-3}$. Nickel is a preferred choice for coatings due to its strength and resistance to surface degradation as well as due to its aesthetic and sparkly visual appeal. Electrolytic method of deposition is selected when it is required to have some control over the crystallite size, surface morphology and orientation of Ni which in turn significantly affects surface related properties of the coatings. Conventionally, Ni coatings have been prepared using dc electrochemical methods ${ }^{4-7}$. More recently, use of pulse electrodeposition has become popular since it results in Ni coatings with refined grain structure ${ }^{8,9}$ and attractive corrosion $^{10-12}$ and tribological properties ${ }^{13-18}$. Pulse plating is undertaken when current is applied in repetitive (pulse on - pulse off) square wave fashion rather than continuously as in dc plating. During pulse electrodeposition, peak current density, pulse on-time and pulse off-time are accurately controlled. Advantages of pulse electrodeposition include its cost effectiveness and high current density, power and range of pulse waveforms available for plating ${ }^{19}$. Pulse electrodeposition results in fine nanostructured coatings which show improvement in properties such as hardness, wear, abrasion, coefficients of friction, etc, compared to those produced by conventional dc plating.

Study of the corrosion behavior of nanostructured coatings is of considerable interest due its potential use as protective coatings in wide ranging applications. Fine grain

*e-mail: amquddus@kfupm.edu.sa structure of nanocoatings results in high volume fraction of intergranular defects due to increased density of grain boundaries and triple junctions. There is a concern that this might have an adverse effect on the localized corrosion behavior of nanocoatings. However, previous studies have shown that $\mathrm{Ni}$ based nanocoatings are resistant to corrosion. Some studies report an improvement in corrosion resistance ${ }^{6,11,12}$ while others show behavior comparable to polycrystalline $\mathrm{Ni}^{10}$. It has also been reported that nanocrystalline $\mathrm{Ni}$ exhibited active-passive-transpassive polarization characteristics similar to coarse-grained polycrystalline $\mathrm{Ni}^{5-6}$.

In the present study, carbon steel samples were treated with sodium dihydrogen orthophosphate $\mathrm{NaH} 2 \mathrm{PO} 4 . \mathrm{H} 2 \mathrm{O}$ inhibitor prior to $\mathrm{Ni}$ electrodeposition. The authors have prior experience with the selected inhibitor because of its efficacy and excellent performance for protecting mild steel exposed to outdoor atmospheric environment ${ }^{20}$. Our aim was to develop an active inhibitor layer underneath $\mathrm{Ni}$ that would provide added protection from corrosion. The idea was to combine beneficial effects of both nanostructured $\mathrm{Ni}$ coatings and that of the inhibitor resulting in an enhanced and long-term protection against corrosion. The effect of inhibitor on the adherence of $\mathrm{Ni}$ coating to the substrate was evaluated. Deposition of Ni was undertaken in Watt's bath using both dc and pulse electrodeposition techniques. Corrosion behavior of Ni coatings as well as inhibited plain carbon steel substrates was studied using Tafel potentiodynamic polarization technique in $3.5 \mathrm{wt} \% \mathrm{NaCl}$ solution. Materials characterization was carried out using 
field emission scanning electron microscopy, cross-sectional scanning transmission electron microscopy, atomic force microscopy, X-ray diffraction and nanoindentation hardness tests. Role of microstructure on the corrosion properties of Ni coatings was examined.

\section{Experimental}

\subsection{Electrodeposition}

Plain carbon steel discs with $16 \mathrm{~mm}$ diameter were metallographically ground and polished to $1 \mu \mathrm{m}$ surface finish. They were degreased with acetone and rinsed with distilled water. The composition of Watt's bath used for this study was NiSO4.6H2O (250 gm), NiCl2.6H2O (50 gm) and $\mathrm{H} 3 \mathrm{BO} 3$ (35 gm) per liter of distilled water. Pure Ni sheet was used as anode and carbon steel as cathode during electrodeposition. The $\mathrm{pH}$ and temperature of the electrolyte was kept at 3.6 and $45^{\circ} \mathrm{C}$, respectively. A current density of $50 \mathrm{~mA} / \mathrm{cm} 2$ was used for dc plating. Pulse electrodeposition was performed at different peak currents of $5 \mathrm{~A}$ for durations of 20 minutes. Pulse on-time (Ton) and off-time (Toff) were set at 2 and $10 \mathrm{msec}$, respectively. Triplicate tests were run for each plating technique used for the present study.

\subsection{Materials characterization}

Atomic force microscope (AFM-contact mode, Agilent 5500 model) and field emission scanning electron microscope (FE-SEM, FEI NOVA NANOSEM 210 model) equipped with scanning transmission electron microscope (STEM) detector (attached to FEI Helios NanoLab) was used to examine the surface morphology and microstructure of electrodeposited Ni. The interface between the substrate and the Ni coating was imaged after preparing a thin cross-sectional sample using focused ion beam (FIB) instrument model FEI Helios NanoLab. An X-ray diffractometer (XRD model Rigaku Ultima IV MPD) equipped with a monochromator was used to determine the phase constitution, grain size and texture of $\mathrm{Ni}$ coatings. The diffraction spectra were generated using $\mathrm{CuK} \alpha$ radiation $\left(\lambda=1.54184 \mathrm{~A}^{\circ}\right)$ source operating at $40 \mathrm{kV}$ and $40 \mathrm{~mA}$. Phase identification was carried out using a Bragg-Brentano (BB) configuration with $\theta / 2 \theta$ scan axis.

Instrumented nanohardness measurements were undertaken using a Berkovich (three-sided pyramid) diamond nanoindenter which penetrated the sample at a load of $100 \mathrm{mN}$ and load/unload speed of $200 \mathrm{mN} / \mathrm{min}$. The indenter remained stationary for 30 seconds between each loading and unloading cycle. The nanohardness data was generated from the normal force versus penetration depth curves. A set of four indentations was acquired for each test. Nanoindentation hardness (HS) is measured as the resistance to permanent deformation or damage and is calculated as follows:

HS $($ Pascal $)=$ Fmax $/$ Ap

Where, Fmax $=$ maximum force $(\mathrm{N})$

Ap $=$ projected contact area $(\mathrm{m} 2)$

\subsection{Corrosion measurements}

Carbon steel substrates were immersed in $10 \mathrm{mM}$ solution of $\mathrm{NaH} 2 \mathrm{PO} 4 . \mathrm{H} 2 \mathrm{O}$ (sodium dihydrogen orthophosphate) inhibitor for a period of 24 hours prior to $\mathrm{Ni}$ electrodeposition. It is noteworthy that $10 \mathrm{mM}$ $\mathrm{NaH} 2 \mathrm{PO} 4 . \mathrm{H} 2 \mathrm{O}$ solution was found optimal in our earlier study $^{20}$. Corrosion tests were carried out in neutral $3.5 \%$ $\mathrm{NaCl}$ solution at $23{ }^{\circ} \mathrm{C}$. Tafel potentiodynamic polarization curves were acquired for $\pm 250 \mathrm{mV}$ potential range with respect to open circuit potential and at a slow scan rate of $0.166 \mathrm{mVs}-1$. A three-electrode cell (EG\&G K-44) was used for corrosion measurements. A standard saturated (with 4M KCl solution) calomel electrode (SCE) was used as reference and the carbon steel samples were employed as working electrodes, whereas the graphite rods were utilized as counter electrode. The tests were controlled through a standard potentiostat/galvanostat EG\&G Model 263A connected to a computer having EG\&G 352 SoftCorr-III Corrosion Measurement Software.

\section{Results and Discussion}

\subsection{Characterization of electrodeposited Ni}

Surface morphology of $\mathrm{Ni}$ obtained using $\mathrm{dc}$ electrodeposition revealed coarse compact pyramidalshaped grains as shown in the SEM micrograph of Figure 1a. Maximum grain size observed was approximately $3 \mu \mathrm{m}$. Pulse electrodeposition produced fine equiaxed grains existing in the form of colonies that are separated by crevices as shown in Figure 1b. Fine surface morphology of pulse electrodeposited Ni was also revealed in the AFM image of Figure $1 \mathrm{c}(Z$-scale $=1.89 \mu \mathrm{m})$. Bright field STEM cross-sectional image of the interface between the substrate and Ni coating for pulse electrodeposit sample is shown in Figure 1d. It is clear that the grain size of Ni coating is small, especially in the initial stages of the deposition where it can be as fine as $\approx 10 \mathrm{~nm}$. The difference in grain morphology obtained by dc and pulse electrodeposition was also shown by a difference in their instrumented nanoindentation hardness. The instrumented nanohardness values of $\mathrm{Ni}$ coatings obtained by dc method was $2492 \mathrm{MPa}(230 \mathrm{VHN})$ compared to $3384 \mathrm{MPa}(313 \mathrm{VHN})$ for pulsed Ni coatings. Refinement in grain size is thought to be responsible for an increase in the hardness of pulse coatings ${ }^{15}$.

Carbon steel samples were dipped in NaH2PO4.H2O inhibitor for 24 hours and the top surface was examined using SEM. Inhibitor was uniformly distributed over the surface and exhibited a spherical morphology as shown in Figure 2a. Microchemical analysis of the top surface using $\mathrm{SEM} / \mathrm{EDS}$ (Figure 2b) showed the presence of $\mathrm{Na}, \mathrm{P}$ and $\mathrm{O}$ from inhibitor and $\mathrm{Fe}$ from underlying carbon steel substrate. The inhibited carbon steel surfaces were deposited with $\mathrm{Ni}$ using dc and pulse plating techniques. Surface morphology of $\mathrm{dc}$ and pulse plated Ni covering inhibited carbon steel (CS) samples is shown in the SEM images of Figures $2 \mathrm{c}$ and $2 \mathrm{~d}$, respectively. Application of a uniform Ni coating was possible and the presence of inhibitor on steel surface did not seem to adversely affect the electrodeposition process.

$\mathrm{x}$-ray diffraction spectrum obtained from the top surface of pulse Ni electrodeposited sample is shown in 


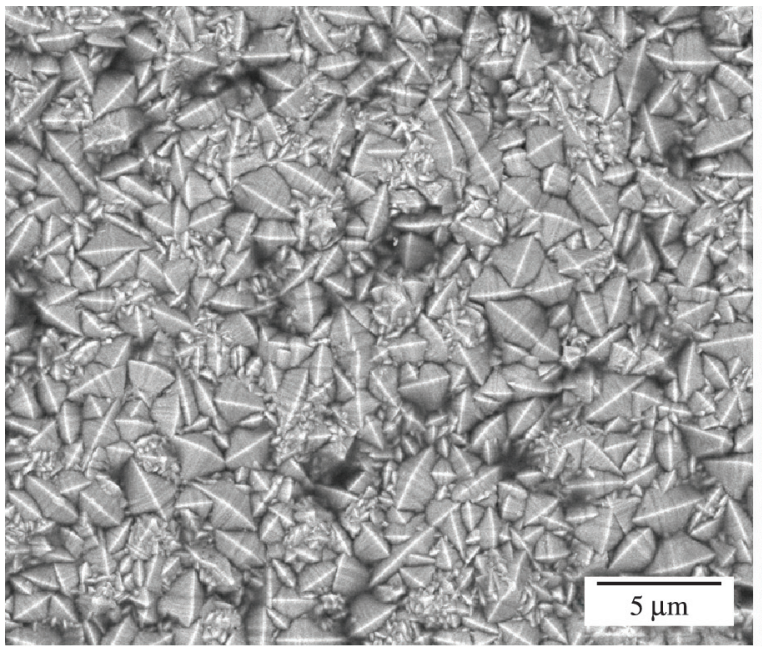

(a)

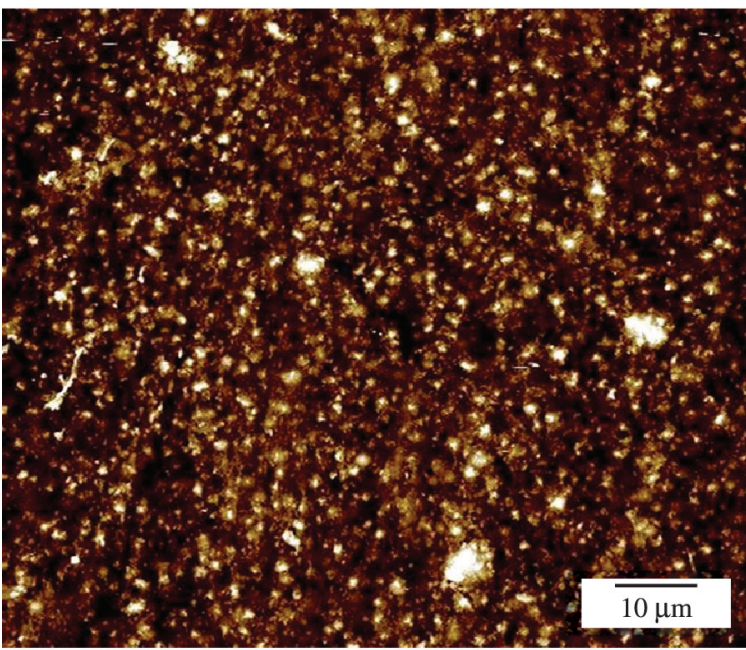

(c)

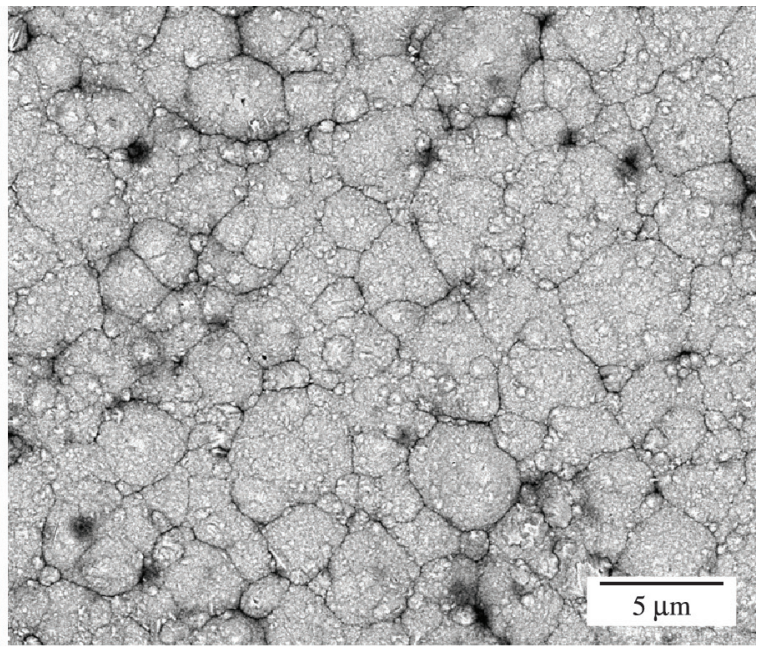

(b)

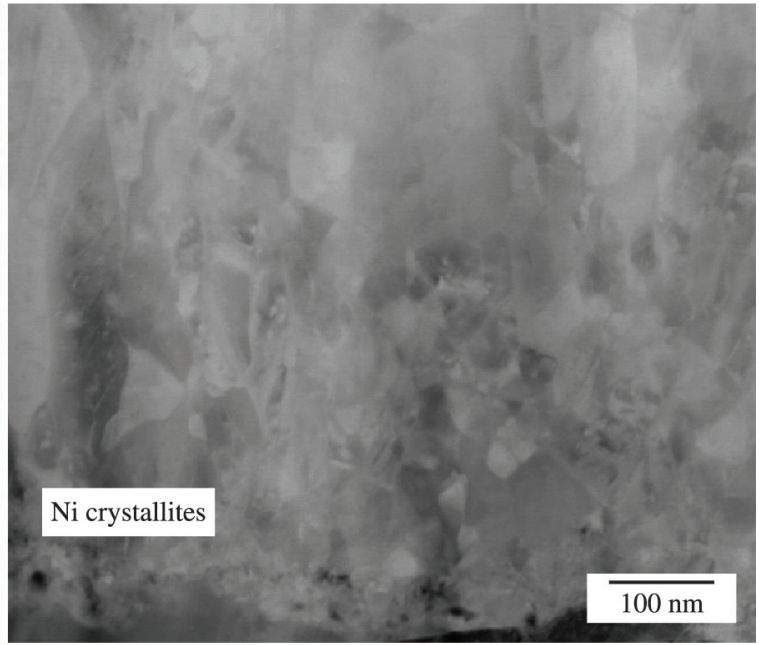

(d)

Figure 1. Surface morphologies of Ni produced by: (a) dc electrodeposition showing coarse pyramidal grains and (b) pulse electrodeposition showing fine equiaxed grains. (c) AFM (scale: $x=100, y=100$ and $z=1.89$ microns, step size 1.4 microns) and (d) Cross-sectional HAADF images of fine grained pulse Ni electrodeposit showing fine-grained structure. (HAADF - High Angle Annular Dark Field).

Figure 3 . The peak with highest intensity corresponds to $\mathrm{Ni}$ (220) indicating preferred orientation. Preferred growth orientation of planes has been reported in literature for pulse deposited $\mathrm{Ni}^{9,13}$.

\subsection{Corrosion measurements}

The typical potentiodynamic polarization (Tafel) plots obtained for $\mathrm{dc}$ and pulse electrodeposited $\mathrm{Ni}$ with and without inhibitor treatments are shown in Figure 4 for the various electrochemical measurements listed in Table 1. As evident from the polarization curves of Figure 4, the zero current potential (ZCP) for treated fine grained Ni was comparatively more noble (positive) than that of untreated fine and coarse grained Ni. This is due to the fact that high grain boundary density in fine grained $\mathrm{Ni}$ influences the hydrogen evolution reaction shifting the potential to more noble values ${ }^{4}$. Also, the corrosion rate (CR) observed for fine grained $\mathrm{Ni}$ was lower than its coarse grained counterpart (Table 1). This is attributed to more compact microstructure of fine grained $\mathrm{Ni}$ electrodeposit that results in an increase in the resistance to anodic dissolution ${ }^{5,12}$.

The electrochemical behavior of inhibitor treated electrodeposits followed a pattern similar to that of untreated electrodeposits. Fine grained Ni exhibited nobler ZCP and lower corrosion rate compared to coarse grained $\mathrm{Ni}$. A comparison between the polarization plots in Figure 4 reveals that electrodeposited Ni treated with inhibitor shows better corrosion properties than untreated Ni. Resistance to corrosion for coarse grained treated coatings is comparable for treated and untreated coatings. The overall corrosion behavior of all 4 types of electrodeposits can be rated from top to bottom (Figure 4) as:

Treated fine-grain Ni (least CR) $<$ Untreated fine-grain $\mathrm{Ni}<$ Untreated coarse-grain $\mathrm{Ni}<$ Treated coarse-grain Ni. 


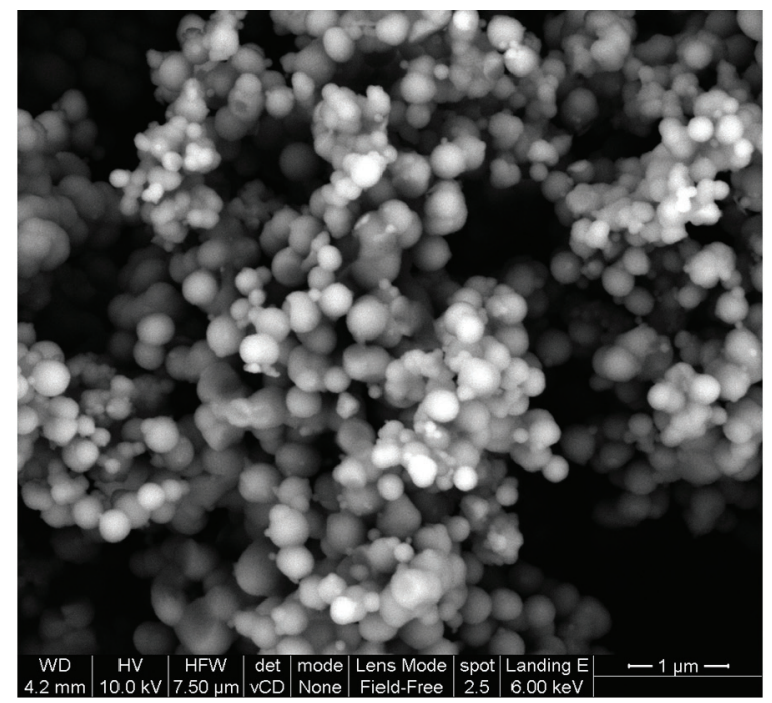

(a)

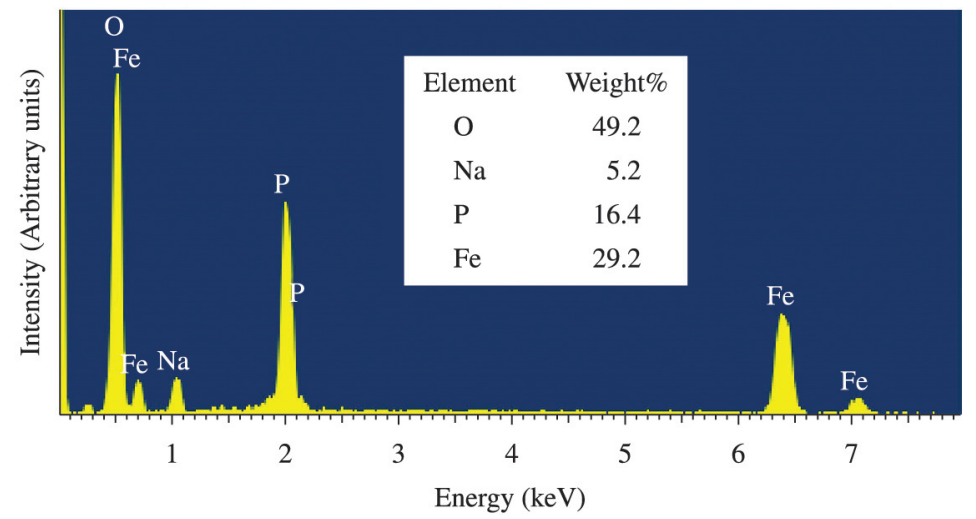

(b)

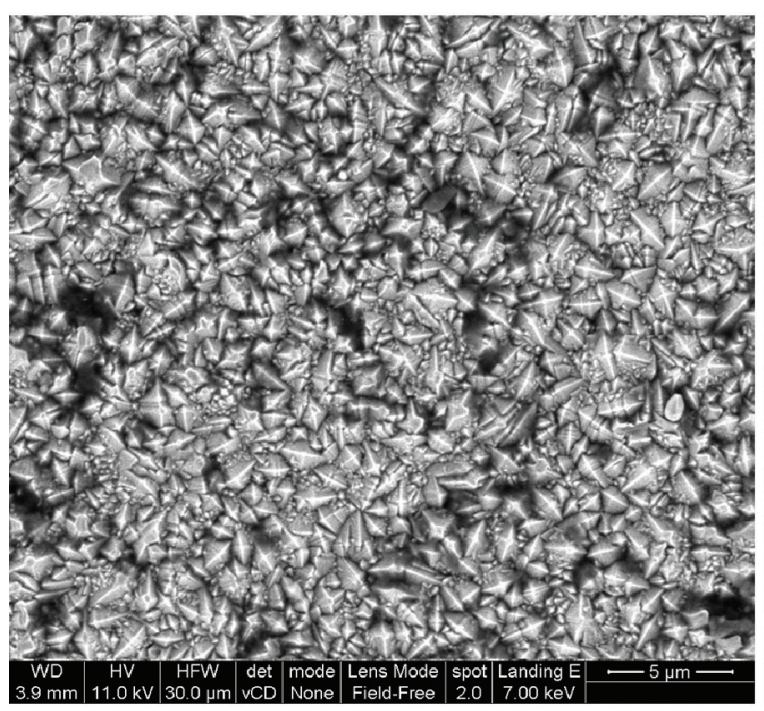

(c)

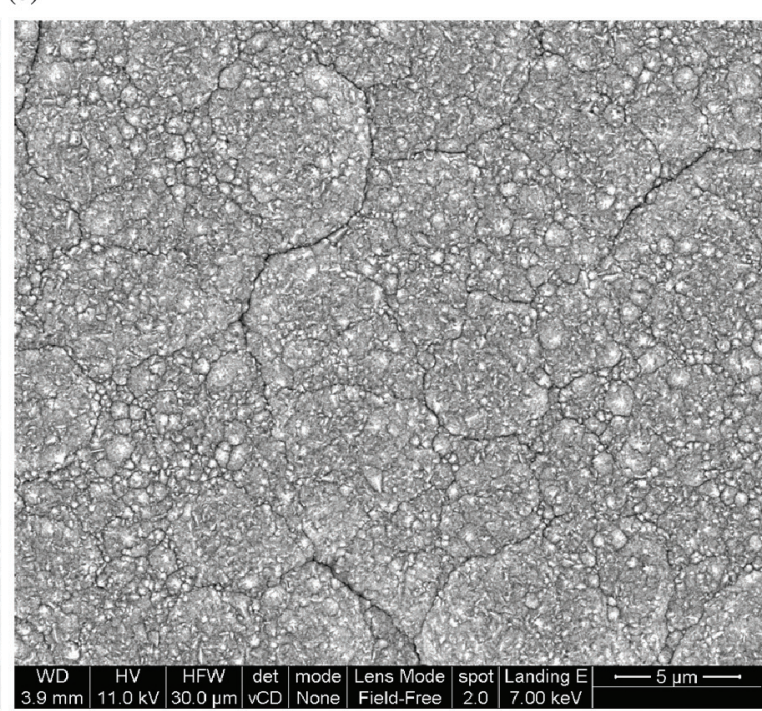

(d)

Figure 2. (a) SEM image and (b) EDS spectrum obtained from NaH2PO4.H2O inhibitor. (c) Surface morphology of (c) dc and (d) pulse plated Ni covering inhibited carbon steel. 
The corrosion rates observed in the present investigation, (Table 1), were not significant. Therefore, on the whole all the dc and pulse plated $\mathrm{Ni}$ coating remained within a range that can be classified as having low corrosion rates as corroborated well with the data found in the literature ${ }^{21}$.

\subsection{Microstructure after polarization tests}

Surface morphology of untreated coarse and fine Ni after polarization is shown in Figures $5 \mathrm{a}$ and $5 \mathrm{~b}$, respectively. Density and depth of pits in coarse grained Ni electrodeposit is higher. Pits are shallower and lower in density in fine grained Ni. Surface morphology of coarse and fine electrodeposits treated with the selected inhibitor is shown in Figure 5c and 5d, respectively. Pit density is significantly lower in fine grained Ni. Surface damage of both treated samples is lower compared to that of untreated samples.

\subsection{Role of inhibitor}

The selected inhibitor, sodium dihydrogen orthophosphate $\mathrm{NaH} 2 \mathrm{PO} 4 . \mathrm{H} 2 \mathrm{O}$ is a film forming inorganic compound capable of retarding both cathodic and anodic reactions on the metals surfaces ${ }^{22}$. Based on our earlier

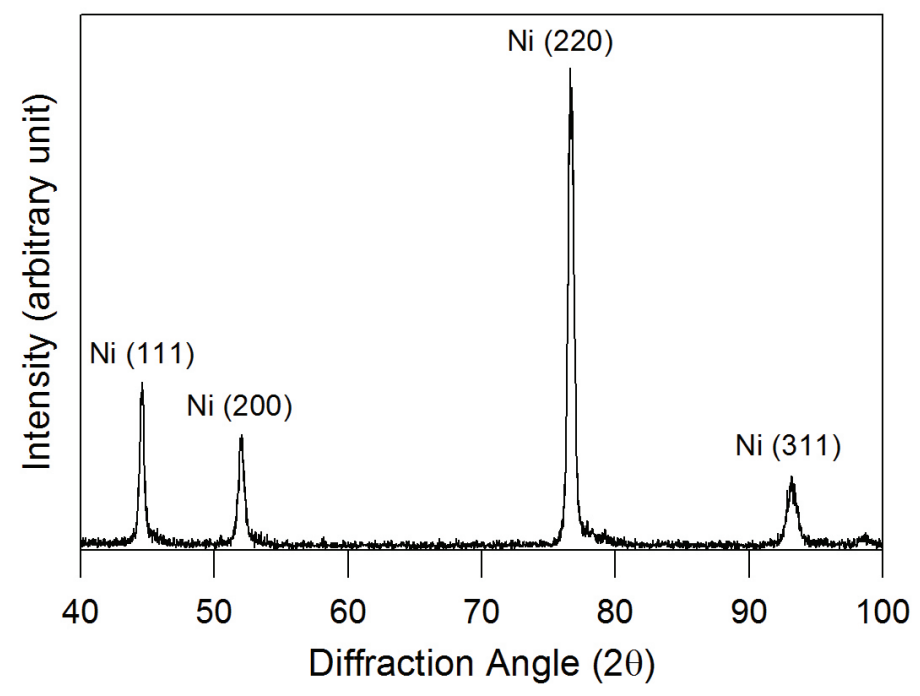

Figure 3. X-ray diffraction patterns XRD pattern obtained from pulse deposited Ni showing (220) preferred orientation.

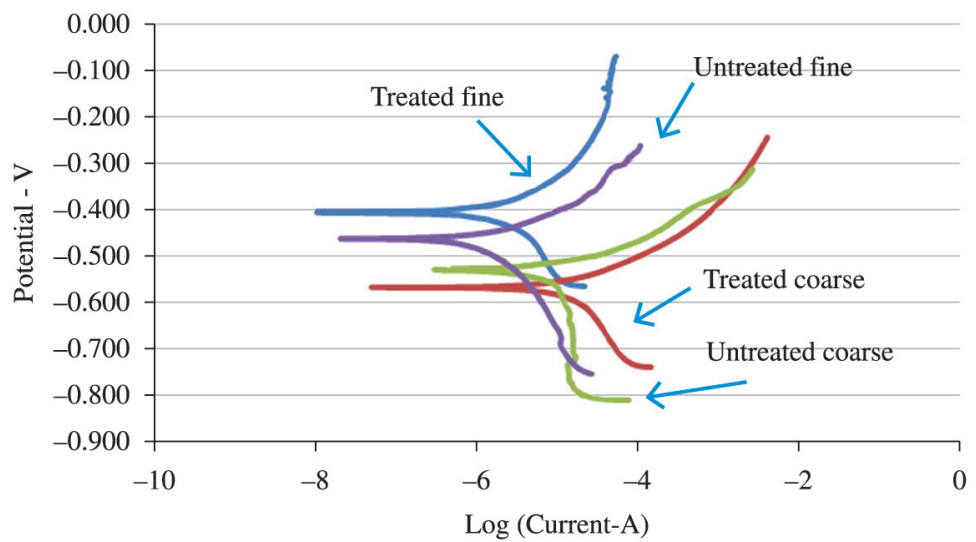

Figure 4. Potentiodynamic polarization (Tafel) plots obtained for coarse and fine Ni deposited on untreated and inhibitor treated carbon steel.

Table 1. Electrochemical measurements obtained from potentiodynamic polarization plots for untreated and inhibitor treated $\mathrm{Ni}$ electrodeposits.

\begin{tabular}{lcccc}
\hline & \multicolumn{2}{c}{ Untreated Ni (without inhibitor) } & \multicolumn{2}{c}{ Treated Ni (with inhibitor) } \\
\hline & Pulse (grain size & DC (grain size & Pulse (grain size & DC (grain size \\
& $<\mathbf{1 0 0} \mathbf{~ n m})$ & $\mathbf{3 ~} \boldsymbol{\mu \mathbf { m }})$ & $<\mathbf{1 0 0} \mathbf{~ n m})$ & $\mathbf{3} \boldsymbol{\mu \mathbf { m } )}$ \\
\hline $\mathrm{ZCP},(\mathrm{mV})$ & -466.2 & -523.5 & -406.5 & -569.1 \\
Corrosion Rate $(\mathrm{CR})-$ mpy & 1.114 & 4.301 & 0.7026 & 4.554 \\
\hline
\end{tabular}




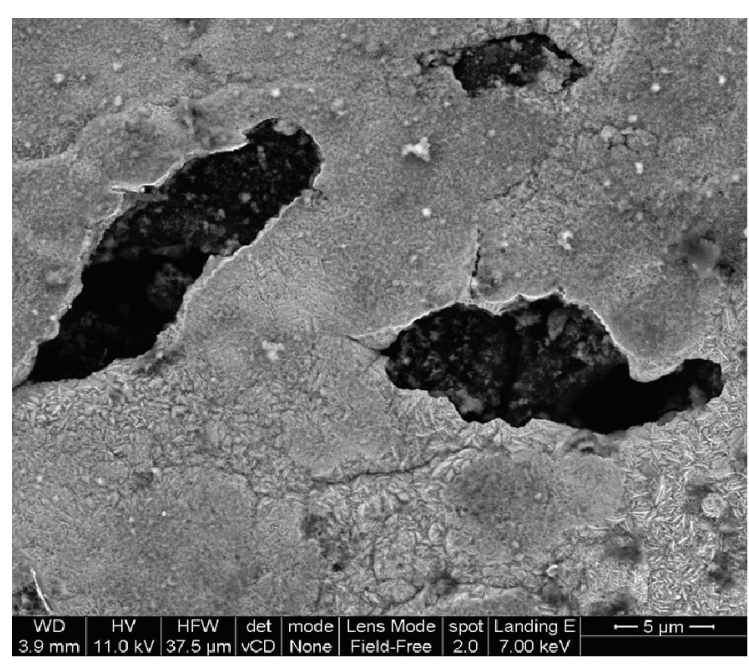

(a)

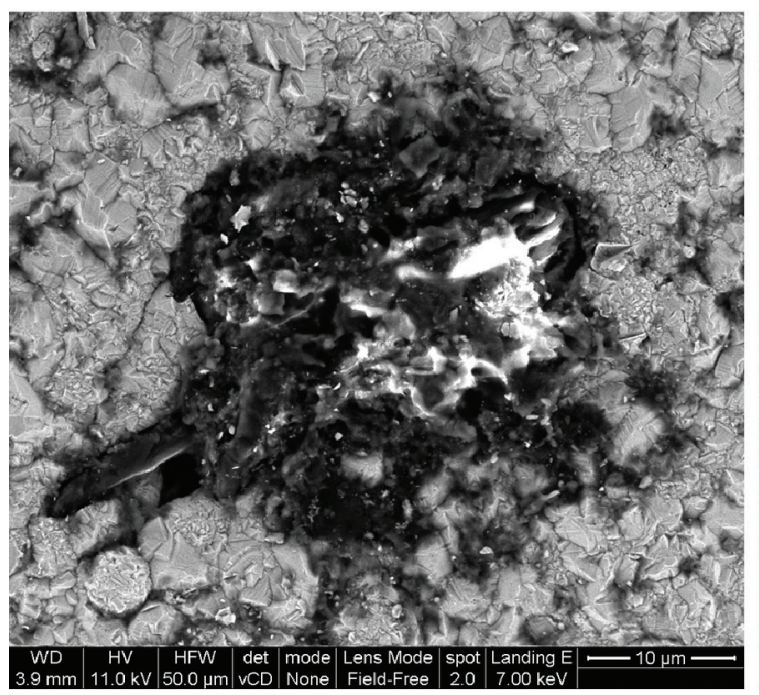

(c)

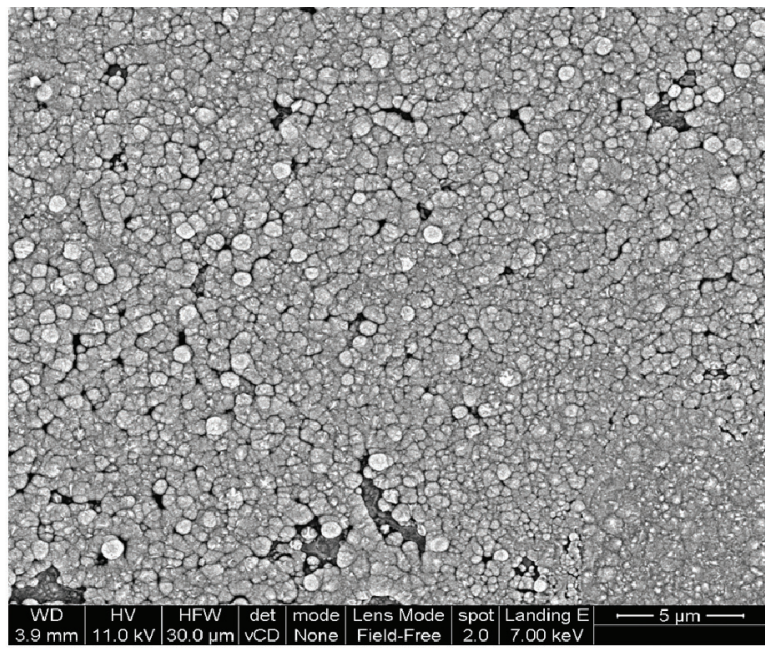

(b)

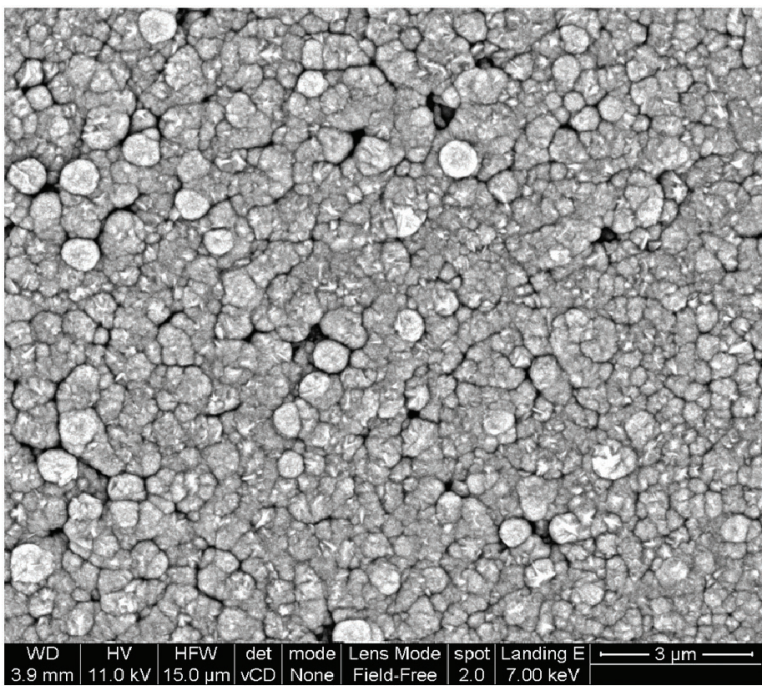

(d)

Figure 5. Surface morphology of Ni electrodeposit after polarization. (a) Coarse and (b) fine Ni on untreated carbon steel. (c) Coarse and (d) fine $\mathrm{Ni}$ on inhibitor-treated $\mathrm{Ni}$.

experience, the inhibitor when used in $10 \mathrm{mM}$ concentration had exhibited outstanding performance in protecting mild steel samples by showing the lowest corrosion rate of treated samples upto 180 days, in both electrochemical and weight loss measurements, and preventing discoloration of treated samples upto 130 days of atmospheric exposure ${ }^{20}$.

In the present study, inhibitor $\mathrm{NaH} 2 \mathrm{PO} 4 . \mathrm{H} 2 \mathrm{O}$ was applied to the surface of the steel substrate prior to inserting it into the Watt's bath for electrodeposition. It was observed that the presence of inhibitor film at the cathode surface did not adversely affect deposition process. Identical deposition parameters were used for treated and untreated samples and uniform, continuous and adherent deposit was obtained in each case. The inhibitor's role became important as the corrosion process progressed. Its incorporation was believed to retard anodic dissolution and enhance corrosion protection of underlying substrate by acting as a barrier layer between the coating and the substrate. Influence of grain size on the corrosion behavior was prominent in this study since layer(s) of inhibitor existed underneath the Ni coating which acted as an impermeable shield against the ingress of corrosive chlorides into the treated plated samples during the polarization tests in $3.5 \mathrm{wt} \% \mathrm{NaCl}$ solution.

\section{Conclusions}

The electrochemical and corrosion behavior of coarse and fine $\mathrm{Ni}$ electrodeposit treated with NaH2PO4.H2O inhibitor were compared with that of untreated $\mathrm{Ni}$ of corresponding grain size in the reported study. The treated fine grained pulse plated $\mathrm{Ni}$ exhibited nobler zero current potential and lower corrosion rate than both treated and untreated Ni pulse and dc-coated samples. The corrosion behavior of treated fine-grained $\mathrm{Ni}$ electrodeposit was found to be better than the untreated fine-grained Ni. Moreover, the treated and untreated pulse plated Ni coated samples 
performed better than that of dc Ni plated samples from corrosion standpoint. No significant corrosion damage was observed in any of the dc and pulse plated Ni coatings that were tested and the corrosion rates remained practically within a low range.

\section{References}

1. Pletcher D and Walsh FC. Industrial electrochemistry. 2nd ed. London: Chapman and Hall; 1990.

2. Dennis JK and Such TE. Nickel and Chromium Plating. London: Butterworth; 1986.

3. Ul-Hamid A, Dafalla H, Quddus A, Saricimen H and AlHadhrami L. Electrochemical deposition of $\mathrm{Ni}$ on an $\mathrm{Al}-\mathrm{Cu}$ alloy. Journal of Materials Engineering and Performance. 2012; 21(2):213-221. http://dx.doi.org/10.1007/s11665-0109816-9.

4. Tuck JR, Korsunsky AM, Davidson RI, Bull SJ and Elliott DM. Modelling of the hardness of electroplated nickel coatings on copper substrates. Surface and Coatings Technology. 2000; 127(1):1-8. http://dx.doi.org/10.1016/S0257-8972(00)00537-5.

5. Chan KC, Chan WK and Qu NS. Effect of current waveform on the deposit quality of electroformed nickels. Journal of Materials Processing Technology. 1999; 89-90:447-450. http:// dx.doi.org/10.1016/S0924-0136(99)00053-9.

6. Zhao H, Liu L, Zhu J, Tang Y and Hu W. Microstructure and corrosion behavior of electrodeposited nickel prepared from a sulphamate bath. Materials Letters. 2007; 61(7):1605-1608. http://dx.doi.org/10.1016/j.matlet.2006.07.178.

7. Ul-Hamid A, Quddus A, Al-Yousef FK, Mohammed AI, Saricimen H and Al-Hadhrami LM. Microstructure and Surface Mechanical Properties of Electrodeposited Ni Coating on Al 2014 alloy. Surface and Coatings Technology. 2010; 205(7):2023-2030. http://dx.doi.org/10.1016/j. surfcoat.2010.08.083.

8. El-Sherik AM and Erb U. Synthesis of bulk nanocrystalline nickel by pulsed electrodeposition. Journal of Materials Science. 1995; 30(22):5743-5749. http://dx.doi.org/10.1007/ BF00356715.

9. El-Sherik AM, Erb U and Page J. Microstructural evolution in pulse plated nickel electrodeposits. Surface and Coatings Technology. 1997; 88(1-3):70-78. http://dx.doi.org/10.1016/ S0257-8972(96)02928-3.

10. Rofagha R, Langer R, El-Sherik AM, Erb U, Palumbo G and Aust KT. The corrosion behavior of nano crystalline nickel. Scripta Metallurgica et Materialia. 1991; 25(12):2867-2872. http://dx.doi.org/10.1016/0956-716X(91)90171-V.

11. Mishra R and Balasubramaniam R. Effect of nanocrystalline grain size on the electrochemical and corrosion behavior of nickel. Corrosion Science. 2004; 46(12):3019-3029. http:// dx.doi.org/10.1016/j.corsci.2004.04.007.

\section{Acknowledgements}

The authors wish to acknowledge the support of the Research Institute at the King Fahd University of Petroleum \& Minerals, Dhahran, Saudi Arabia.

12. Yang C, Yang Z, An M, Zhang J, Tu Z and Li C. The effect of direct-reverse pulse parameters on the morphology and corrosion resistance of nickel deposits. Plating and Surface Finishing. 2001; 88(5):116-118.

13. Xuetao Y, Yu W, Dongbai S and Hongying Y. Influence of pulse parameters of the microstructure and microhardness of nickel electrodeposits. Surface and Coatings Technology. 2008; 202(9):1895-1903. http://dx.doi.org/10.1016/j. surfcoat.2007.08.023.

14. Mishra R, Basu B and Balasubramaniam R. Effect of grain size on the tribological behavior of nanocrystalline nickel. Materials Science and Engineering A. 2004; 373(1-2):370-373. http:// dx.doi.org/10.1016/j.msea.2003.09.107.

15. Shen YF, Xue WY, Wang YD, Liu ZY and Zuo L. Mechanical properties of nanocrystalline nickel film deposited by pulse plating. Surface and Coatings Technology. 2008; 202(21):51405145. http://dx.doi.org/10.1016/j.surfcoat.2008.05.027.

16. Jeong DH, Gonzalez F, Palumbo G, Aust KT and Erb $\mathrm{U}$. The effect of grain size on the wear properties of electrodeposited nanocrystalline nickel coatings. Scripta Materialia. 2001; 44(3):493-499. http://dx.doi.org/10.1016/ S1359-6462(00)00625-4

17. Chen L, Wang L, Zeng $\mathrm{Z}$ and $\mathrm{Xu} \mathrm{T}$. Influence of pulse frequency on the microstructure and wear resistance of electrodeposited Ni-A12O3 composite coatings. Surface and Coatings Technology. 2006; 201(3-4):599-605. http://dx.doi. org/10.1016/j.surfcoat.2005.12.008.

18. Ul-Hamid A, Dafalla H, Quddus A, Saricimen H and AlHadhrami LM. Microstructure and Surface Mechanical Properties of Pulse Electrodeposited Nickel. Applied Surface Science. 2011; 257(22):9251-9259. http://dx.doi.org/10.1016/j. apsusc.2011.04.120

19. Choo RJC, Toguri JM, El-Sherik AM and Erb U. Mass transfer and electro crystallization analysis of nanocrystalline nickel production by pulse plating. Journal of Applied Electrochemistry. 1995; 25(4):384-403. http://dx.doi. org/10.1007/BF00249659.

20. Malaibari Z, Kahraman R, Saricimen H and Quddus A. Investigation of atmospheric corrosion of mild steel after treatment by several inhibitor solutions, Corrosion Engineering. Science and Technology. 2007; 42(2):112-118.

21. Fontana MG and Greene ND. Corrosion engineering. 2 nd ed. New York: McGraw-Hill Book Company; 1978.

22. Khan IH. Corrosion technology. Lahore: Institute of Chemical Engineering Technology, University of the Punjab; 1989. 561 p. v. 1 . 